\title{
Formación sociolingüística e intercultural para profesores de ELE en contexto de diversidad lingüística: un estudio de caso en la frontera Brasil-Bolivia
}

\author{
Viviane Ferreira Martins (D) @ \\ Universidad Complutense de Madrid y Universidad Pontificia de Comillas, España
}

Resumen. Los contextos sociolingüísticamente complejos, como son las zonas de frontera con lenguas en contacto, demandan una enseñanza de lenguas acorde con sus especificidades. En este sentido, el estudio es una propuesta de formación docente de base sociolingüística e intercultural para los profesores de español como lengua extranjera (ELE) de la frontera de Brasil con Bolivia, en concreto la ciudad brasileña de Cáceres. Las lenguas en la zona, el portugués, el español, el portuñol y lenguas indígenas, ocupan posiciones jerárquicas que responden a las relaciones de desigualdad y prejuicios entre los individuos de diferentes orígenes étnicos o de diferentes nacionalidades. Las conclusiones, obtenidas, por una parte, mediante el diagnóstico de la situación sociolingüística, de las actitudes y de la presencia de las lenguas en el sistema educativo y, por otra parte, a partir del diagnóstico de la formación de base sociolingüística de los profesores de ELE, nos llevan a afirmar que la formación que proponemos puede ser un importante factor para el desarrollo de la interculturalidad y del plurilingüismo en la región y, además, puede servir como modelo para la enseñanza de lenguas extranjeras en otros contextos de diversidad lingüística.

Palabras clave: frontera; enseñanza de lenguas extranjeras; formación docente; interculturalidad; sociolingüística.

\begin{abstract}
Formação sociolinguística e intercultural para professores de ELE em contexto de diversidade linguística: um estudo de caso na fronteira Brasil-Bolívia

Resumo. Os contextos sociolinguisticamente complexos, como as áreas de fronteira com línguas em contato, exigem um ensino de línguas de acordo com as suas especificidades. Neste sentido, o estudo é uma proposta de formação docente de base sociolinguística e intercultural para os professores de espanhol como língua estrangeira (ELE) da fronteira do Brasil com a Bolívia, especificamente da cidade brasileira de Cáceres. As línguas da região, o português, o espanhol, o portunhol e as línguas indígenas, ocupam posições hierárquicas que respondem às relações de desigualdade e preconceito entre indivíduos de diferentes etnias ou de diferentes nacionalidades. As conclusões, obtidas, por um lado, mediante o diagnóstico da situação sociolinguística, das atitudes e da presença das línguas no sistema educativo e, por outro lado, a partir do diagnóstico da formação sociolinguística dos professores da ELE, permitiram-nos afirmar que a formação que propomos pode ser um fator importante para o desenvolvimento da interculturalidade e do plurilinguismo na região e, além disso, pode servir como modelo para o ensino de línguas estrangeiras em outros contextos de diversidade lingüística.
\end{abstract}

Palavras-chave: fronteira; ensino de línguas estrangeiras; formação de professores; interculturalidade; sociolinguística.

\section{Sociolinguistic and intercultural training for SFL teachers in a context of linguistic diversity: a case study on the border Brazil-Bolivia}

Abstract. Complex sociolinguistic contexts, like border areas where several languages are in contact, demand the teaching of languages according to their specific features. In this way, this study is a proposal for educational training based on sociolinguistcs and interculture for teachers of Spanish as a foreign language (SFL) on the border between Bolivia and Brazil, specifically, in the Brazilian city of Cáceres. Languages in this area, Portuguese, Spanish, Portunhol and indigenous languages, take a hierarchical position, showing a relationship of inequality among individuals from different ethnic groups or nationalities. Our conclusions are obtained, on the one hand, according to the assessment of the sociolinguistic situation, attitudes and presence of these languages in the educational system and, on the other hand, to the assessment of training with sociolinguistic base for SFL teachers, and we are able to affirm that the training which we are proposing, could be a crucial factor in order to improve interculturality and multilingualism in that area and, in addition, it could be used as a model for teaching foreign languages in another contexts where we can find linguistic diversity.

Keywords: border; teaching of foreign languages; educational training; interculturality; sociolinguistics. 


\section{Introducción}

En las fronteras, como espacio superdiverso (Vertovec, 2007) caracterizado por las migraciones y la estratificación social, en algunos casos, las lenguas se distribuyen a nivel de escalas verticales de espacio-tiempo (familia, nacional, local, institucional, periférico) en las que las lenguas se legitiman o deslegitiman, así como las identidades asociadas a ellas (Blommaert, 2007, 2010). La correspondencia entre los grupos sociales y sus privilegios económicos en el plano de las lenguas, conlleva, a que los intercambios lingüísticos reflejen las relaciones de poder simbólico donde se actualizan las relaciones de poder y fuerza (Bourdieu, 1988 [1979], 1985 [1982]). El lenguaje, por ende, es capaz de reproducir formas de desigualdad o de mantener una estructura de jerarquía social (Bauman y Briggs, 2003).

En este sentido, si el profesorado de lenguas posee, entre otros aspectos, una formación de base sociolingüística e intercultural, las clases pueden convertirse en un elemento clave en el desarrollo de la interculturalidad y de una actitud positiva frente a la diversidad sociocultural, étnica y lingüística con el potencial de visibilizar el poder de las lenguas como factor de justicia social (Piller, 2016).

Esta formación debe, necesariamente, desarrollar en el docente los saberes y competencias que van más allá del funcionamiento estrictamente lingüístico de la lengua que enseña. La competencia lingüística del profesor de lenguas extranjeras es requisito para el buen desempeño de su trabajo, pero hay otros conocimientos que superan los aspectos lingüísticos, que son tan importantes como dicha competencia. A este conjunto de saberes que pueden favorecer un proceso de enseñanza-aprendizaje más eficaz de la LE, según las particularidades de cada contexto, principalmente en zonas de diversidad lingüística, es lo que llamamos formación sociolingüística e intercultural.

En consonancia con este planteamiento, diversos estudios defienden de forma significativa la presencia de la contextualización sociocultural en la enseñanza de lenguas, tanto en la enseñanza de L1 (Bortoni-Ricardo 2005; Bagno, 2015; Bugel, 2000; Fanjul, 2004), como en la enseñanza de LE (Preston y Young 2000; Moreno, 1994, 2010).

La enseñanza de lenguas en situaciones de diversidad social, cultural, étnica y lingüística (como en las fronteras brasileñas) tiene necesidades específicas y, por tanto, debe partir de una formación docente diferenciada, fundamentada en la sociolingüística, considerando esta desde una visión amplia a partir de la relación dialéctica entre lengua, sociedad y cultura (Williams, 1983). Este campo de la lingüística se preocupa por los aspectos 
que relacionan lengua y contexto social, abarcando una gran diversidad de temas que fueron tomados por la lingüística aplicada en su objetivo de perfeccionar cada vez más el proceso de enseñanza de lenguas.

Sin embargo, consideramos que es especialmente relevante e innovador ampliar la unión de la lingüística aplicada y de la sociolingüística con parámetros que no se consideraron hasta el presente momento en la enseñanza de español en muchas regiones de Brasil: i) diferenciación de regiones de frontera como un contexto geográfico, sociocultural y lingüístico que demanda un proceso de enseñanza aprendizaje de ELE de acuerdo con sus particularidades; y ii) diferenciación en la formación de profesores de ELE en las regiones fronterizas con países de lengua española.

Desde esta perspectiva, el presente trabajo es un estudio teórico experimental sobre la formación de base sociolingüística de profesores de español como lengua extranjera (ELE) en la frontera Brasil-Bolivia, en la ciudad de Cáceres, ubicada en el Estado de Mato Grosso, en la Región Centro Oeste de Brasil. Las lenguas presentes en esta frontera son el portugués, el español, el portuñol y lenguas indígenas.

Siguiendo las ideas anteriores, los objetivos de esta investigación son, por un lado, comprobar la necesidad de una formación de base sociolingüística e intercultural, mediante la realización de un diagnóstico de la situación sociolingüística, de las actitudes y de la presencia de las lenguas en el sistema educativo de Cáceres; y, por otro lado, averiguar si los profesores de ELE de la ciudad poseen o no una formación de base sociolingüística e intercultural que pueda contribuir a la integración de los individuos de diferentes orígenes, a la interculturalidad y a la consolidación del español y del multilingüismo en la frontera.

\section{Formación sociolingüística e intercultural}

Níkleva y Rico-Marín (2017, p. 11) cuestionan si, para enseñar español a James, un niño inglés, “¿qué es más importante: saber bien español o conocer bien a James?". Sin desconsiderar la necesidad de que el profesorado sepa español, los autores, de forma rotunda, otorgan más importancia al conocimiento del alumno. De acuerdo con este planteamiento, el docente tiene que conocer los factores sociolingüísticos que rodean al alumnado que tienen influencia directa en la enseñanza-aprendizaje de la lengua. Estos factores incluyen el conocimiento del repertorio lingüístico 
del estudiante, la situación sociolingüística local, las relaciones de poder y actitudes entre las lenguas y su influencia en la motivación hacia el estudio y uso de determinadas lenguas.

Con el fin de cumplir estos objetivos, seleccionamos algunos ámbitos temáticos provenientes de la sociolingüística que pueden apoyar la construcción de una enseñanza de LE capaz de armonizar los conflictos y las tensiones sociales oriundas de la diversidad sociocultural, étnica y lingüística y, de esta forma, motivar el aprendizaje y uso de la lengua, a saber: i) variación y variedades lingüísticas; ii) política y planificación lingüísticas; iii) actitudes lingüísticas; iv) valor positivo do bilingüismo / plurilingüismo y, por último, v) interculturalidad.

En una formación a partir de este enfoque sociolingüístico e intercultural, que edifica la enseñanza de la lengua según las características locales y que considera factores extralingüísticos, si el docente sabe analizar el impacto del estatus de las lenguas y de las variedades lingüísticas en la enseñanza y sabe tratarlas desde el punto de vista igualitario (Trudgill y Hernández, 2007; Penny, 2004; Moreno, 2000, 2008; Kramsh, 1993; Del Valle, 2002 [1999]); si conoce las políticas lingüísticas que afectan el multilingüismo y la enseñanza de lenguas con potencial de convertirse en un agente de cambio hacia la defensa de la diversidad lingüística y del plurilingüismo como factor de justicia social (Fill y Mühlhausler, 2001; Tollefson, 2005, Phillipson, 1996; Piller, 2016; Pérez-Milans y Soto, 2016; Calvet, 1999); si relaciona las creencias y las actitudes lingüísticas al mantenimiento o desaparición de las lenguas dentro y fuera del sistema educativo (Lambert y Lambert, 1966 [1964]; Bem, 1970; Baker, 1992; López, 1993; Saville-Troike, 2003; Santos, 1996); si valora positivamente el bilingüismo y el plurilingüismo de su región a partir del conocimiento de sus ventajas sociales, psicológicas y cognitivas (Bain, 1975; Cummins, 1979, 1986; Tunmer y Myhill, 1984, Pinto, 1993; Baker, 1997 [1993]); si conoce los principios de la interculturalidad y su aplicación a la enseñanza de lenguas (Byram; 1997; Ogay, 2000); estará más capacitado para construir una práctica docente de acuerdo con las especificidades y demandas propias a favor del plurilingüismo y de la interculturalidad.

Sobre el estatus de las lenguas y de las variedades lingüísticas en la región delimitada para nuestro estudio de caso, la ciudad brasileña de Cáceres en la frontera con Bolivia, las distintas lenguas y sus correspondientes variedades -el portugués, el español, el portuñol y las lenguas indígenasposeen estatus diferenciados, y su tratamiento adecuado en la enseñanza puede favorecer el contacto con la diversidad cultural de la zona. En el caso particular del español, a través de las variedades lingüísticas de Bolivia, se puede enseñar símbolos y elementos culturales que pongan en evidencia voces olvidadas o silenciadas en la zona. La enseñanza del español en Brasil 
puede ser un espacio en el que el alumnado pueda ir más allá de conocer los símbolos socioculturales, por los que el hispanismo es comúnmente asociado; $y$, en algunos casos, poder ver por primera vez la belleza de un vecino oculto, que siempre ha estado cerca.

Respecto a la formación en el ámbito de política y planificación lingüísticas, la formación teórica sobre los documentos nacionales y regionales ha de estar unida: i) a la necesidad de concienciación de la búsqueda permanente de la información sobre el tema en cuestión, debido a los constantes cambios, y ii) al permanente análisis sobre su correspondencia y adecuación a su contexto educativo concreto. A diferencia de los primeros modelos de política y planificación lingüísticas (Haugen, 1959) en los que los agentes estaban claramente identificables, por ejemplo, lingüistas y agentes políticos, en la actualidad todos somos agentes de la política lingüística en el sentido de que las micro intervenciones tienen un papel destacado. El docente, con una formación de esta índole, tendrá un mayor potencial para analizar los cambios en la política lingüística nacional y regional y convertirse en un factor de cambio hacia la garantía de la diversidad lingüística y del plurilingüismo de su alumnado.

En lo que concierne a las actitudes lingüísticas, los profesores de lenguas deben promover que el alumnado se plantee cuestiones referentes a la diversidad lingüística, a los prejuicios lingüísticos y a las actitudes hacia las lenguas que componen el panorama sociolingüístico local. Estas temáticas son de extrema importancia para la composición del currículo de un docente en zonas de frontera (Berger, 2015). En la enseñanza de lenguas en la frontera, las creencias sobre la comunidad de habla vecina y el consecuente desarrollo de una actitud positiva o negativa hacia sus hablantes y hacia su lengua, son factores clave de influencia para la motivación de los estudiantes para aprender la lengua del otro y para la construcción de una sociedad que sepa valorar la diversidad cultural, social y lingüística.

Por su parte, el bilingüismo y el plurilingüismo son temas fundamentales para la formación del docente en contextos fronterizos de diversidad lingüística, ya que es esencial que conozca sus ventajas sociales y cognitivas. De esta manera, el profesorado puede trasmitir a su alumnado los beneficios de ser bilingüe o plurilingüe, lo que apoya la preservación del bilingüismo o plurilingüismo del alumnado.

Por último, es de extrema necesidad que el profesorado conozca el concepto de interculturalidad, su importancia en el actual mundo globalizado, su aplicación en la enseñanza de lenguas y, por ende, el papel destacado del aula de lenguas en el desarrollo de dicha competencia. 
Los temas seleccionados deben, a su vez, ser presentados al profesorado siempre en relación con su contexto y desde una perspectiva crítica que considere la relación de poder entre las lenguas. Ello conlleva un acercamiento hacia la lingüística aplicada crítica (Pennycook, 2001, 2006, 2010, 2013; Rajagopalan, 2003, 2007; Lopes, 2006); entre otros, y un tratamiento metodológico que fomente la reflexión constante sobre el propio entorno. Por otra parte, el profesorado debe, en contextos fronterizos de asimetría entre las lenguas, visibilizar los colectivos históricamente marginados y sus correspondientes culturas. Para facilitar esta tarea, en unión con los temas sociolingüísticos, se pueden añadir teorías y conceptos que introducen un cambio hacia nuevas epistemologías. Entre ellos destacamos las teorías del pensamiento decolonial de Mignolo (2007) y Quijano (2007), las epistemologías del sur de Santos (2010, 2012, 2014) y, por último, los conceptos de colonialismo interno y cadenas de dominación de Rivera (2010a [1984], 2010b). Estas teorías pueden ayudar al profesorado a entender las relaciones asimétricas entre los colectivos fronterizos.

El objetivo del presente estudio no es ofrecer una descripción y análisis exhaustivos de los ámbitos temáticos que han sido presentados, sino más bien pretendemos alertar, a partir del diagnóstico sociolingüístico local y de la formación del profesorado de ELE de la zona estudiada, sobre la necesidad de incluir estos temas de índole sociolingüística e intercultural en la formación docente de regiones multilingües de frontera. Los planteamientos teóricos de cada tema propuesto han sido descritos y detallados como parte de una investigación doctoral previa (Ferreira Martins, 2018).

\section{El estudio}

El estudio de caso conforma como una investigación cualitativa, con datos cuantitativos. Para cumplir los objetivos propuestos de comprobar la necesidad de una formación de base sociolingüística e intercultural, por una parte y, por otra parte, averiguar si los profesores de ELE de Cáceres poseen o no una formación de base sociolingüística e intercultural, nos planteamos realizar:

i) Diagnóstico de los elementos que rodean esta formación del profesorado e ELE: situación sociolingüística local y presencia de las lenguas en el sistema educativo

ii) Diagnóstico de la formación de base sociolingüística e intercultural de los profesores de ELE en los siguientes ámbitos temáticos:

— variación y variedades lingüísticas;

- política y planificación lingüísticas; 
- actitudes lingüísticas;

— bilingüismo / plurilingüismo;

- interculturalidad.

Dividimos las fuentes de recogida de datos en

- Fuentes primarias: profesores de ELE

- Fuentes secundarias: i) documentos oficiales (Secretaría de Educación de Mato Grosso - SEDUC y Ayuntamiento de Cáceres); ii) Comunidad hispanohablante.

Iniciamos la recopilación de datos en febrero de 2016. Los datos fueron recogidos por etapas, a través de varios instrumentos: i) cuestionario, ii) sesión reflexiva, iii) portafolio docente, iv) entrevista y v) investigación documental. A continuación, presentamos el diseño de las etapas y los instrumentos de recogida de la información:

Tabla 1

\begin{tabular}{|c|c|c|}
\hline \multicolumn{3}{|c|}{ Fuentes secundarias } \\
\hline $1^{\text {a }}$ etapa & Documentos oficiales & $\begin{array}{l}\text { Presencial y a distancia } \\
\text { Enero de } 2016 \text { a junio de } 2017\end{array}$ \\
\hline $2^{\mathrm{a}}$ etapa & $\begin{array}{l}\text { Entrevistas (comunidad } \\
\text { hispanohablante) }\end{array}$ & $\begin{array}{l}\text { Presencial } \\
\text { Periodo: julio de } 2017\end{array}$ \\
\hline \multicolumn{3}{|c|}{ Fuentes primarias } \\
\hline $1^{\text {a }}$ etapa & Cuestionario & $\begin{array}{l}\text { Online: software libre Google Forms } \\
\text { Periodo: diciembre de } 2016 \text { a junio de } 2017\end{array}$ \\
\hline \multirow{2}{*}{$2^{\mathrm{a}}$ etapa } & sesión reflexiva & $\begin{array}{l}\text { Presencial } \\
\text { Periodo: julio de } 2017\end{array}$ \\
\hline & portafolio docente & $\begin{array}{l}\text { Presencial: Julio de } 2017 \\
\text { A distancia: Agosto a octubre de } 2017\end{array}$ \\
\hline
\end{tabular}

Fuente: elaboración propia.

La sesión reflexiva y portafolio docente tenían el objetivo añadido de servir como herramienta de reflexión y autoformación docente bajo la metodología de la investigación-acción (Schön, 1983, 2000 [1998]). Ambos instrumentos se insertaron en un curso ofrecido a los profesores de ELE de Cáceres, Porto Esperidião y Vila Bela da Santíssima Trindade (estas dos localidades son pueblos cercanos a Cáceres que presentan una situación sociolingüística semejante), con un total de 27 participantes. El curso consistió, en un primer momento, en la realización de una sesión reflexiva sobre los ámbitos temáticos analizados, y posteriormente, en una formación de base teórica sobre los mismos temas. En la última etapa del curso elaboramos el portafolio docente con el profesorado. El curso contó con la colaboración de diversas instituciones locales. 
Respecto a las fuentes primarias, conforme la siguiente tabla, tenemos 11 profesores de español, lo que corresponde al 64\% del profesorado de español en activo de Cáceres, según datos oficiales. La muestra es, en definitiva, significativa, sobre todo si consideramos la distribución de los profesores en las escuelas de Cáceres: contamos con participantes presentes en el $100 \%$ de los de las escuelas públicas que ofrecen ELE y en el $67 \%$ de las escuelas privadas.

\begin{tabular}{lllllll}
\multicolumn{1}{l}{ Tabla 2} & \multicolumn{1}{l}{$l$} & \\
\hline P & \multicolumn{1}{c}{ Nacimiento } & Sexo & Residencia & $\begin{array}{c}\text { Año de } \\
\text { nacimiento }\end{array}$ & Edad & Lengua materna \\
P1 & Cáceres & Mujer & Cáceres & 1983 & 34 & Portugués \\
P2 & $\begin{array}{l}\text { Vila Bela da Santíssi- } \\
\text { ma Trindade }\end{array}$ & Mujer & Cáceres & 1978 & 39 & Portugués y español \\
P3 & Fernandes Tourinho & Mujer & Cáceres & 1966 & 51 & Portugués \\
P4 & Cáceres & Mujer & Cáceres & 1980 & 37 & Portugués \\
P5 & Cáceres & Mujer & Cáceres & 1993 & 24 & Portugués yespañol \\
P6 & Cáceres & Hombre & Cáceres & 1974 & 43 & Portugués \\
P7 & Cáceres & Hombre & Cáceres & 1995 & 22 & Portugués \\
P8 & Rio Branco & Mujer & Cáceres & 1978 & 39 & Portugués \\
P9 & Salto de Céu & Mujer & Cáceres & 1984 & 33 & Portugués \\
P10 & Conceição das Alagoas & Mujer & Cáceres & 1975 & 42 & Portugués \\
P11 & Cáceres & Mujer & Cáceres & 1983 & 34 & Portugués y español \\
\hline
\end{tabular}

Fuente: elaboración propia.

La mayoría de los participantes son mujeres (9 de 11) y la media de edad es de 36 años. Solo dos profesores nacieron fuera de la frontera (P3 y P10), pero se mudaron para Mato Grosso cuando aún eran muy jóvenes. Ocho de los 11 profesores tienen el portugués como lengua materna y tres son bilingües portugués-español porque son hijos de bolivianos (aunque uno de ellos no se haya declarado bilingüe - P2).

Sobre los participantes secundarios, realizamos un total de 6 entrevistas a la comunidad boliviana hispanohablante local, 5 de ellas en los comercios habitualmente ocupados por los bolivianos y una en el consulado de Bolivia. En el formato de la entrevista semiestructurada, seguimos un guion temático y, a partir de preguntas abiertas, los participantes podían expresar sus opiniones, matizar sus respuestas, e incluso desviarse hacia otros temas. Los temas centrales eran: i) las lenguas que utilizan en la familia y demás situaciones cotidianas, y ii) las actitudes hacia el español y hacia la comunidad boliviana en Cáceres. 
Tabla 3

\begin{tabular}{cll}
\hline Fuentes Secundarias (EPS) & Sexo & Edad \\
\hline EPS1 & Mujer & 35 años \\
EPS2 & Mujer & 55 años \\
EPS3 & Mujer & 25 años \\
EPS4 & Mujer & 49 años \\
EPS5 & Mujer & 23 años \\
EPS6 & Hombre & 46 años \\
\hline
\end{tabular}

Fuente: elaboración propia.

A partir de investigación documental, analizamos diversos informes oficiales sobre los alumnos y los profesores de las escuelas de Cáceres, así como el Plan Municipal de Educación.

En el diagnóstico de la situación sociolingüística y de las lenguas en el sistema educativo, nos centramos en las entrevistas de la comunidad boliviana y en los documentos oficiales. Asimismo, consideramos la percepción del profesorado acerca de la relación de poder entre las lenguas. En la parte de la formación del profesorado, están los resultados de los cuestionarios, de las sesiones reflexivas y del portafolio docente de los profesores de ELE.

\subsection{Frontera Brasil-Bolivia. Cáceres: situación sociolingüística, actitudes y las lenguas en el sistema educativo}

La frontera de Mato Grosso ha sido, desde sus inicios, marcada por el afán de ocupación y protección territorial y por la diversidad étnica y sociocultural, con muchos elementos conectados histórica y socialmente con Bolivia. Parte del territorio del actual Mato Grosso perteneció a Bolivia hasta 1903 (Cerveira de Sena, 2012). No obstante, a pesar de una confluencia sociocultural e histórica, unida a una extensa frontera con un país hispanohablante (la de mayor extensión, con 3.423,2 km) no hay iniciativas concretas de integración fronteriza entre Brasil y Bolivia, sea a partir del Proyecto de Desarrollo de la Franja de Frontera (Brasil, 2009) u otros acuerdos bilaterales.

Mato Grosso comporta numerosas lenguas indígenas, siendo el segundo estado del país en materia de diversidad lingüística y en número de población que se auto declara indígena (IBGE, 2010). Desgraciadamente, los continuos esfuerzos civiles y gubernamentales en defensa de los pueblos indígenas todavía no son suficientes y la presión económica por la ocupación de la tierra por grandes latifundistas, por industrias nacionales y multinacionales, les está despojando de sus derechos, lo que también conlleva a la desaparición de su lengua y su cultura. 
Cáceres es la principal ciudad de la frontera de Brasil con Bolivia, desde el punto de vista poblacional, económico o cercanía y acceso con el país vecino. Ubicada a orilla del Río Paraguay y a $80 \mathrm{~km}$ de San Matías (Bolivia), tiene una presencia significativa de población de origen boliviano. Además, está presente la comunidad indígena chiquitana, pero con escasos hablantes de su lengua ubicados fuera de los centros urbanos en zona de protección indígena tutelados por la Fundación Nacional del Indio (FUNAI). Las lenguas presentes, por lo tanto, son el portugués, el español, el chiquitano y el portuñol. La ciudad, insertada en el contexto socio histórico de Mato Grosso, cuya configuración fronteriza se ha edificado bajo los ideales de ocupación, defensa y unidad nacional (Bernadino, 2015; Amedi, 2012), posee una frontera con una visión negativa sobre la diversidad.

Según las entrevistas realizadas en Cáceres, observamos que las identidades en esta frontera van a configurarse bajo los criterios de nacionalidad y etnia: identidad brasileña, identidad boliviana e identidad indígena. Estas identidades se distribuyen claramente en posiciones jerárquicas basadas en representaciones estigmatizadas sobre los bolivianos y los indígenas producidas en el lado brasileño de la frontera. El estatus económico de la comunidad asociada a cada cultura determina, en algunas ocasiones, los sentimientos de pertenencia a los ámbitos identitario-culturales y el rechazo a otro u otros, el mayor estatus económico de Brasil ante el más bajo estatus de Bolivia.

Cáceres está marcada por el tránsito constante de personas a los dos lados de la frontera, lo que delimita una frontera física sin mayor significación (EPS2 y EPS6). Asimismo, está definida por la circulación de mercancías ilícitas -drogas y coches robados-, actividad normalmente asociada por los brasileños a los bolivianos (EPS4 y EPS5). La prensa local suele dar énfasis a este punto de vista, lo que ejerce gran influencia en el discurso sobre los bolivianos (P3). Este hecho es fácilmente demostrable, ya sea en la prensa escrita o en la digital de la ciudad.

Gran parte de los bolivianos realizan sus actividades laborales en los comercios y los brasileños reconocen el comercio como un espacio donde predominan bolivianos (EPS3). Los comerciantes bolivianos se quejan de que, en ocasiones, los clientes brasileños se dirigen a ellos de forma despectiva (EPS2, EPS4, EPS5). Además, la propia ubicación de su actividad comercial es fruto de prejuicios (EPS5, Ferreira, 2017). Identificamos la ausencia de integración entre los bolivianos (EPS1, EPS4, EPS5), que quizás, puede tener sus raíces en el desprestigio que tiene Bolivia en la zona. 
Del mismo modo, para la comunidad boliviana, podemos afirmar a partir de la percepción del profesorado, que los indígenas de Cáceres son vistos de una forma negativa por los habitantes de la ciudad. Dicha discriminación hacia los indígenas es consecuencia de una larga trayectoria en Brasil de minorización cultural y étnica que les atribuye estereotipos peyorativos como borrachos, animales, incapaces, y antropófagos (Santana, 2014, p. 93). Una vez más, estas actitudes tendrán consecuencias lingüísticas. La lengua chiquitana en Cáceres es hablada por un número pequeño (casi insignificante) de la población indígena de edad más avanzada (EPS2; Santana y Cintra, 2009). Los datos oficiales tampoco indican el número de hablantes de chiquitano en Brasil. Lo que sí es cierto, es que la cifra disminuye constantemente y se hace cada vez más urgente, iniciativas de valoración y difusión para que la lengua no se extinga. Destacamos, además, que los chiquitanos, normalmente, son asociados por los brasileños a la nacionalidad boliviana. Por lo que vemos la negación por parte de los brasileños de la identidad indígena.

Las actitudes negativas hacia los bolivianos y los indígenas tienen clara correspondencia en las lenguas y va a ser el principal factor de configuración de la situación lingüística de Cáceres. En esta óptica, el portugués es la lengua mayoritaria en la frontera, hablado por los brasileños, por los inmigrantes bolivianos y por el pueblo chiquitano. El español es una lengua presente, pero en situación de disminución de su número de hablantes nativos y no nativos puesto que, según veremos a continuación, la lengua también está en retroceso en el sistema educativo. Es destacable el abandono del español por los hablantes de las nuevas generaciones (EPS1, EPS3, EPS4 y EPS5). El portuñol y el chiquitano, ambos asociados a los bolivianos, están estigmatizados.

En el sistema educativo la situación es similar, ya sea en la oferta de lenguas, o sea en el plurilingüismo del alumnado. La presencia del español en las escuelas de Cáceres es escasa, conforme la tabla a continuación.

Tabla 4

\begin{tabular}{lccr}
\hline & $\begin{array}{c}\text { Número de } \\
\text { escuelas }\end{array}$ & $\begin{array}{c}\text { Número de escuelas que } \\
\text { ofertan español }\end{array}$ & $\%$ \\
\hline Escuelas Estaduales & 17 & 8 & $47 \%$ \\
Escuelas Municipales & 86 & 0 & $0 \%$ \\
Escuelas Privadas & 9 & 6 & $66 \%$ \\
Total & 112 & 14 & $13 \%$ \\
\hline
\end{tabular}

Fuente: elaboración propia. 
La ausencia del español en las escuelas municipales es significativa porque son las más numerosas y es en estas donde se imparte la educación primaria. Las clases de lengua española desde edades tempranas permitirían consolidar la adquisición de la lengua a los estudiantes de la región. Por otra parte, el $66 \%$ de las escuelas privadas ofrece español. Estas escuelas prácticamente no tienen alumnos bolivianos y, por tanto, la decisión de ofertar el español no se debe a la necesidad de integración lingüística y valoración cultural del alumnado hispanohablante. En total, de las 112 escuelas del municipio, entre municipales, estaduales y privadas, solo 14 ofrecen la lengua española, lo que corresponde a un $13 \%$.

De forma similar, el Plan Municipal de Educación de Cáceres. Compromiso con el Futuro 2015-2025 (Ayuntamiento de Cáceres, 2015), del Ayuntamiento de Cáceres aprobado por la Ley 2.482 de 22 de junio de 2015 tampoco ubica al alumnado boliviano en las 17 metas que presenta, ya sea con la inclusión de su lengua materna en el sistema educativo, o sea con la enseñanza del portugués de forma particularizada a sus necesidades.

Las escuelas de Cáceres presentan la hegemonía del portugués como la única que posee el estatus de lengua materna. Ello contradice el perfil sociolingüístico de parte del alumnado boliviano. El portugués es hablado por todos los alumnos -brasileños, bolivianos y chiquitanos-. El uso del español en la escuela por parte del alumnado de origen boliviano, como resultado de la actitud negativa hacia Bolivia, es cada vez menos frecuente. Por añadidura, las actitudes negativas hacia los bolivianos y hacia su lengua también están presentes en las escuelas (EPS2, EPS5).

El rechazo de la identidad indígena está presente en el alumnado de Cáceres (Duarte, 2014). No hay registros o estudios sobre el número de hablantes de chiquitano en las escuelas. Con todo, el profesorado señala la presencia de chiquitanos, pero no reconocen su identidad.

Para finalizar este apartado, destacamos que los estereotipos y prejuicios hacia los bolivianos y los indígenas configuran una frontera marcada por relaciones de colonialismo interno y una cadena de dominación (Rivera, 2010a [1984] y 2010b) en la que se observa un colectivo y su respectiva cultura (los brasileños) ocupando una posición superior, mientras los bolivianos y los indígenas (los chiquitanos) son los de abajo. En otras palabras, observamos en Cáceres la correspondencia de la estratificación social en el plano lingüístico. La realidad sociocultural y económica asimétrica reproduce el capital cultural y habitus lingüístico (Bourdieu, 1988 [1979], 1985 [1982]) de la clase dominante: los brasileños. 
Como conclusión, podemos caracterizar Cáceres como un contexto superdiverso (Vertovec, 2007) marcado por la migración constante de bolivianos y por la estratificación socioeconómica y étnica entre brasileños, bolivianos y chiquitanos. La visibilización y la distribución de las lenguas funcionan a nivel de escalas (Blommaert, 2007) en las que las lenguas cobran distintos valores, es decir, adquieren su valor simbólico y son indexicalizadas en niveles de mayor o menor prestigio. En esta línea, el español ocupa la escala familiar y es desplazado cada vez más del ámbito educativo. Además, no está presente en el ámbito institucional. Es más, también está siendo desplazado del ámbito familiar ya que las nuevas generaciones de origen boliviano abandonan cada vez más su lengua materna y se niegan a usar la lengua incluso con los padres (EPS2, EPS4 y EPS5). En las escalas global-periférico, el chiquitano, como representante de la diversidad de lenguas indígenas de Mato Grosso y de Brasil, ha sido totalmente desplazado a la periferia, ya que los pocos hablantes que la usan residen en las comunidades indígenas chiquitanas muy alejadas del centro urbano (en las llamadas tribus indígenas). La presencia del portugués como lengua global (ámbito institucional, educativo, familiar, sea urbano o rural) y su autoridad frente al español y al chiquitano conlleva la legitimación de las voces del grupo social con la que esta lengua se identifica, los brasileños. Esta configuración escalar está influenciada por las actitudes culturales y lingüísticas que desplazan al español y al chiquitano a espacios cada vez más periféricos.

\subsection{Formación del profesorado}

Vamos a presentar, en primer lugar, el análisis de los datos recogidos en el cuestionario y en la sesión reflexiva, ambos realizados antes del módulo de formación teórica del curso. Las conclusiones se refieren al análisis de los datos del cuestionario y de su validación en la sesión reflexiva. Posteriormente, presentaremos los cambios verificados entre el profesorado tras la formación a partir del análisis del portafolio docente.

De forma esquemática, la formación de los docentes de ELE de Cáceres, antes del módulo teórico del curso, podría resumirse, en cada ámbito temático analizado, de la siguiente manera:

\section{Variedades de lingüísticas}

- Escasa visibilidad de la variedad boliviana, incluso los profesores bilingües nacidos en Bolivia o hijos de padres bolivianos nacidos en Brasil.

- Persistencia del prestigio de la variedad castellana presente en la valorización del profesorado, en la formación docente que recibieron en las universidades, en los materiales didácticos 
usados en la región y en las clases. La mayoría del profesorado trabaja con esta variedad en clase y, por lo general, no valoran positivamente la inclusión de las demás variedades.

- Consideración de las variedades del español en dos bloques, España y América, sin el debido reconocimiento de las variedades lingüísticas que estas dos regiones presentan.

- Consideración de la variedad estándar, sin la consideración del pluricentrismo de la lengua española.

- Falta de conocimiento sobre los tipos de variedades de la lengua. Confunden variedad diatópica con otros tipos de variedades (diastrácticas y diafásicas).

- Confunden los conceptos de lengua materna, lengua extranjera, segunda lengua y lengua oficial.

\section{Interculturalidad}

- Escaso conocimiento de las bases teóricas del concepto de interculturalidad en la enseñanza de lenguas.

- Escasa visibilización de la diversidad sociocultural local, tanto de la comunidad boliviana, como de la comunidad indígena.

- Reconocimiento de la necesidad de trabajar la interculturalidad debido al prejuicio y estereotipos detectados en la región, pero con la dificultad de llevarlo a cabo en la práctica docente.

Plurilingüismo y bilingüismo

- Ocultación de la diversidad lingüística de Brasil.

- Sensibilización al plurilingüismo relacionado con las lenguas extranjeras de difusión internacional, y no respeto a las lenguas maternas de Brasil.

- Ausencia de una visión positiva del bilingüismo portugués-español en el ámbito educativo.

\section{Actitudes lingüísticas}

- Escasa percepción de la comunidad chiquitana y, por tanto, invisibilidad de su lengua y de su cultura.

- Reconocimiento de la discriminación con respecto a los indígenas y bolivianos en el contexto escolar.

- Dificultad para trabajar el tema de las actitudes lingüísticas en las escuelas.

- Escasa capacidad de percepción de casos de prejuicio lingüístico.

- Poco conocimiento de conceptos relacionados con las actitudes lingüísticas como prejuicio lingüístico e identidad lingüística. 


\section{Política lingüística}

- Poco conocimiento de los documentos nacionales de planificación lingüística y educativa.

- Escasa percepción del papel del profesorado en el marco de la política y planificación lingüística local.

Después del curso ofrecido al profesorado, verificamos un incremento en la formación del profesorado en todos los ámbitos temáticos anteriormente analizados. Recordemos que realizamos una formación teórica seguida de las sesiones reflexivas y de la elaboración del portafolio docente, ambas propuestas basadas en la investigación-acción con el fin de fomentar la formación mediante la propia práctica docente.

Respecto a la temática de variación y variedades lingüísticas, vemos un cambio en la visión del profesorado respecto a la valoración e inclusión de las distintas variedades del español en las clases, que se corresponde con el $90 \%$ de los participantes. Esta cifra en el cuestionario era del 36\%. El $100 \%$ de los profesores defiende el tratamiento de variedades de Bolivia, la cifra anterior era de $18 \%$. Por tanto, vemos un claro avance en la valoración de la diversidad lingüística del español, sobre todo del español de Bolivia, así como en la defensa de su tratamiento en las clases.

Sobre política y planificación lingüísticas, los datos del portafolio muestran un cambio significativo en el grado de conocimiento de la legislación nacional en materia lingüística y educativa. Los datos anteriores en los que el $100 \%$ del profesorado no demostraba conocimiento del tratamiento de lenguas maternas y lenguas extranjeras de los documentos nacionales y regionales, avanzan significativamente en el sentido de que, aunque algunos manifiestan un bajo conocimiento, la mayoría demuestra el incremento de su conocimiento en esta materia. Por lo tanto, concluimos que los participantes de la investigación demostraron, de forma general, un alto grado de asimilación de los contenidos del curso. Consideramos que este conocimiento, así como los debates de la sesión reflexiva, pueden significar una mayor sensibilización con respecto a su poder de participación como agente activo en la política lingüística y educativa local.

En lo que se refiere a las actitudes lingüísticas, en el portafolio, la mayoría del profesorado manifiesta que tiene un alto grado de capacidad para abordar de forma pedagógica las actitudes lingüísticas en sus clases. No obstante, si volvemos a los datos anteriores, eran escasas la percepción de la presencia chiquitana (como representantes de diferentes etnias en las escuelas) y la actitud claramente positiva hacia los indígenas. Además, el profesorado presentaba muy baja capacidad para detectar casos de prejuicio 
lingüístico. En definitiva, el curso ha sido un elemento de sensibilización hacia la valoración de los colectivos y etnias marginados de la zona, así como los elementos socioculturales y las lenguas asociados a ellos. Sin embargo, para que sepamos si dicha capacidad se concreta en la práctica, sería necesaria una investigación específica, tanto para acceder a las actitudes del profesorado, como para realizar una observación en su práctica docente para saber si hay un tratamiento adecuado de las actitudes en las clases.

Concerniente al plurilingüismo y al bilingüismo, la mayoría de los profesores pasan a relatar la necesidad de que el profesorado sea capaz de valorar positivamente el potencial y bagaje de los alumnos de otras culturas. De forma similar, indican una valoración positiva del bilingüismo portuguésespañol del alumnado como factor positivo para el aprendizaje de otras lenguas.

En el último ámbito temático, el de la cultura y la interculturalidad en las clases, todos los profesores destacaron la importancia de incluir elementos socioculturales del país fronterizo en las clases de español. Sin embargo, recordemos que el cuestionario demostraba una escasa visibilización de la diversidad sociocultural local, tanto de la comunidad boliviana, como de la comunidad indígena. Asimismo, observamos una evolución en la valoración del otro y de su cultura, así como en el conocimiento del concepto de interculturalidad y su aplicación en las clases, si lo comparamos con los datos del cuestionario y de la sesión reflexiva. Con todo, sigue siendo uno de los puntos en los que declaran más dificultad desde el punto de vista de plasmarlo a la práctica docente.

Por los datos presentados, podemos concluir que, como estaba previsto, el portafolio ha cumplido el objetivo de servir como herramienta de reflexión y autoformación sociolingüística de los profesores y ha sido una contribución al cambio de mentalidad del profesorado. No sabemos en qué medida este conocimiento revela un cambio real en la práctica del aula, pero la sensibilización y el mayor acercamiento a los presupuestos de la sociolingüística es un indicativo de que las clases de español pueden convertirse en un espacio para, más allá de desarrollar la competencia comunicativa del alumnado en la lengua extranjera, facilitar la valoración del otro, el pensamiento crítico y la interculturalidad.

\section{Conclusiones}

Podemos concluir que, tanto la situación sociolingüística y educativa como las carencias en la formación del profesorado, justifican nuestra propuesta de formación docente de base sociolingüística e intercultural. 
Es más, los resultados obtenidos nos llevan a considerar que, tanto la metodología utilizada en el estudio como las bases de la formación docente propuestas pueden servir de modelo y soporte para el profesor de otras LE tanto de Brasil como de otros países en zonas de diversidad lingüística. Sin embargo, destacamos la necesidad de realización de un diagnóstico para cada caso concreto, y de esta forma, adaptar y elaborar una formación particularizada.

En Cáceres, el sistema educativo niega la cultura y la lengua del alumnado de diferentes orígenes o nacionalidades y refleja en la práctica la política lingüística nacional construida a partir de una ideología monolingüe y monocultural. En definitiva, es clara la falta de políticas lingüísticas y públicas que reconozcan la importancia de las lenguas autóctonas y extranjeras. Éstas podrían fomentar la relación de convivencia armónica entre la población que habita la frontera y, a la vez, colaborar a la consolidación del plurilingüismo, o en última instancia del bilingüismo, valorando las diversidad sociocultural y lingüística local. Con todo, señalamos un camino alternativo en el que las políticas lingüísticas y públicas emerjan de agentes no institucionales, en concreto del profesorado con una formación apropiada para afrontar y analizar las contradicciones existentes entre la realidad sociolingüística, el sistema educativo y el nivel político e institucional.

Los ámbitos temáticos propuestos se relacionan de forma directa con las necesidades específicas en la formación de profesores de español en la frontera de Mato Grosso con Bolivia desde una perspectiva sociolingüística. Estas necesidades se refieren a los conocimientos y habilidades que apoyan el trabajo docente en su tarea de:

- Analizar la planificación lingüística nacional y local y proponer cambios

- Analizar el contexto y las demandas sociolingüísticas y educativas locales

- Seleccionar las lenguas y las variedades lingüísticas para componer la enseñanza de la lengua

- Aprovechar el conocimiento lingüístico previo de los alumnos

- Crear entre el alumnado la conciencia del valor positivo del plurilingüismo en las lenguas locales

- Desarrollar una actitud positiva hacia las lenguas de la zona

- Desarrollar la interculturalidad entre los alumnos 
Añadimos que la formación de profesores, incluyendo la formación sociolingüística que proponemos, no puede ser vista como un producto que se alcanza al final de cuatro o cinco años de carrera universitaria o tras un curso de formación continua, sino como parte de un proceso que dura una vida entera y tiene un importante factor de renovación. Los temas y conceptos que desarrollamos a lo largo del estudio deben constituir la base a partir de la cual el docente en dicha frontera será capaz de reflexionar sobre la diversidad lingüística como factor de inclusión social y construir su práctica pedagógica bajo esta ideología. A esta capacidad que ayudará a reducir tensiones y desigualdades, nombramos de competencia sociolingüística crítica

En esta nueva competencia, el profesorado adquiere la conciencia de que su formación lingüística en contextos de asimetrías étnicas, sociales, raciales y culturales va unida a un proyecto sociopolítico más amplio de defensa por la igualdad. En esta perspectiva, la consolidación de la enseñanza del español en Cáceres está ligada al fin de la discriminación hacia la comunidad boliviana. Y para incidir en esta problemática, hemos de relacionarla con los otros colectivos marginados, como las comunidades indígenas de la zona. Recordemos que el boliviano está normalmente asociado a la etnia indígena y, por tanto, resignificar y valorar una cultura, Ileva a la aceptación de la otra. En el plano lingüístico, el desarrollo de la actitud positiva hacia el español favorece el cambio de actitud hacia el chiquitano y viceversa.

La formación ofrecida ya ha tenido resultados concretos. Los profesores que han participado del curso están, en la actualidad, en fase de creación de la Asociación de Profesores de Lenguas de la Frontera Oeste de Mato Grosso - APLEFRON / MT cuyo objetivo es, por un lado, incidir en la formación de los profesores de lenguas desde una perspectiva de frontera y, por otro lado, desarrollar acciones a favor del mantenimiento de la diversidad lingüística local. De forma similar, verificamos la creación de dos líneas de investigación en tercer ciclo con temáticas de lenguas en la frontera en la Universidad del Estado de Mato Grosso (UNEMAT) y, además, dos tesis sobre dicha temática fueron iniciadas por profesores participantes de la investigación (P4 y P10).

Para terminar, concluimos que una formación sociolingüística e intercultural es un elemento clave para forjar nuevas trayectorias lingüísticas de aceptación del bilingüismo y del plurilingüismo y para la elaboración y el fomento de políticas e iniciativas lingüísticas que satisfagan las necesidades comunicativas de regiones multilingües de frontera. 


\section{Referencias bibliográficas}

Amedi, N. (2012). A cidade (res)significada: a ideología de modernização de Cuiabá no período pós-divisão do Estado do Mato Grosso. Revista Angelus Novus, 4, 41-64.

Ayuntamiento de Cáceres. (2015). Plan Municipal de Educación de Cáceres. Compromiso con el Futuro 2015-2025.

Bagno, M. (2015). Preconceito linguístico. São Paulo: Parábola Editorial.

Bain, B. (1975). Toward an integration of Piaget and Vygotsky: Bilingual considerations. Linguistics, 160, 5-20.

Baker, C. (1992). Attitudes and Language. Clevedon: Multilingual Matters.

Baker, C. (1997 [1993]). Fundamentos de educación bilingüe y bilingüismo. Madrid: Cátedra.

Bauman, R. Y Briggs, C. L. (2003). Voices of Modernity. Language Ideologies and the Politics of Inequality. Cambridge: Cambridge University Press.

Bem, D. J. (1970). Beliefs, attitudes and human affairs. Belmont: Brooks/Cole.

Berger, I. (2015). Atitudes de professores brasileiros diante da presença do espanhol e do guarani em escolas na fronteira Brasil - Paraguai: elemento à gestão de línguas. Signo y Seña, 28, 169-185.

Bernardino, M. G. (2015). Redesenhando a fronteira noroeste: a Carta de Mato Grosso e Regiões Circunvizinhas (1917-1952). Terra Brasilis. Revista da Rede Brasileira de História da Geografia e Geografia Histórica, 6, 1-13.

Blommaert, J. (2007). Sociolinguistic scales. Intercultural Pragmatics, 4(1), 1-19.

Blommaert, J. (2010). The sociolinguistics of globalization. Cambridge: Cambridge University Press.

Bortoni-Ricardo, S. M. (2005). Nós cheguemu na escola, e agora? Sociolingüística e Educação. São Paulo: Parábola.

Bourdieu, P. (1985 [1982]). ¿Qué significa hablar? Madrid: Ediciones Akal.

Bourdieu, P. (1988 [1979]). La distinción. Madrid: Taurus.

Brasil. (2009). Ministerio de Integración Nacional. Programa de Desarrollo de la Franja de Frontera.

Bugel, T. (2000). Aspectos ideológicos y culturales de la enseñanza actual del español como lengua extranjera en la ciudad de San Pablo - Brasil. Actas del XI Congreso de ASELE, 239-246.

Byram, M. (1997). Teaching and Assessing Intercultural Communicative Competence. Clevedon: Multilingual Matters.

Calvet, L. J. (1999). La guerre des langues et les politiques linguistiques. Paris: Hachette Littératures.

Cerveira de Sena, E. (2012). De colônias al início dos Estados Nacionais: Considerações sobre a fronteira entre Brasil e Bolívia. Revista Territórios \& Fronteiras, 5, 114-130. 
Cummins, J. (1979). Cognitive/academic language proficiency, linguistic interdependence, the optimum age question and some other matters. Working Papers on Bilingualism, 19, 121-129.

Cummins, J. (1986). Empowering minority students: A framework for intervention.

Harvard Educational Review, 56, 18-36.

Del Valle, J. (2002 [1999]). Lenguas imaginadas: Menéndez Pidal, la lingüística hispánica y la configuración del estándar. Estudios de Lingüística Aplicada (ELiEs), 16, s.p.

Duarte, A. N. D. A. (2014). O chiquitano de Cáceres-MT: contribuições para a constituição da escola como fronteira interétnica e intercultural. Dissertação(Mestrado). Universidade do Estado de Mato Grosso. Disponível em https://bit.ly/2ZgClxM

Fanjul, A. (2004). Português brasileiro, espanhol de... onde? analogias incertas. Letras \& Letras, 20(1), 165-183.

Ferreira Martins, V. (2018). Formación Sociolingüística para profesores de ELE en Brasil. Tesis Doctoral. Universidad Complutense de Madrid y Universidad de Brasilia.

Fill, A. y Mühlhäusler, P. (Eds.). (2001). The Ecolinguistics Reader: Language, Ecology and Environment. New York: Continuum.

Haugen, E. (1959). Planning for a Standard Language in Modern Norwey. Anthropological Linguistics, 1(3), 8-21.

IBGE. (2010). Instituto Brasileño de Geografía y Estadística. Disponible en http://www.ibge.gov. br/home/ (Fecha de acceso: 10/07/2019)

Kramsch, C. (1993). Context and Culture in Language Teaching. Oxford: Oxford University Press.

Lambert, W. A, y Lambert, W. E. (1966 [1964]). Psicologia Social. Rio de Janeiro: Zahar Editors.

Lopes, L. P. (Ed.). (2006). Por uma linguística aplicada interdisliplinar. São Paulo: Parábola.

López Morales, H. (1993). Sociolingüística. Madrid: Editorial Gredos.

Mignolo, W. (2003). Historias locales/diseños globales: Colonialidad, conocimientos subalternos y pensamiento fronterizo. Madrid: Akal Ediciones.

Moreno, F. (1994). Aportes de la sociolingüística a la enseñanza de lenguas. Revista Reale, 1994, 107-135.

Moreno, F. (2010). Las variedades de la lengua española y su enseñanza. Madrid: Arco Libros.

Moreno, J. C. (2000). La dignidad e igualdad de las lenguas. Crítica de la discriminación lingüística. Madrid: Alianza Editorial.

Moreno, J. C. (2008). El nacionalismo lingüístico. Una ideología destructiva. Barcelona: Ediciones Península.

Níkleva, D. G. y Rico-Marín, A. M. (2017). El papel del professor de español como lengua extranjera o segunda y las necesidades en su formación. En Níkleva, D. G. (ed.). Necesidades y tendencias en la fromación del profesorado de español como lengua extranjera (11-37). Bern: Peter Lang.

Ogay, T. (2000). De la compétence à la dynamique Interculturelles. Bern: Peter Lang. 
Penny, R. (2004 [2000]). Variación y cambio en español. Madrid: Gredos.

Pennycook, A. (2001). Critical applied linguistics. A critical introduction. New York: Routledge.

Pennycook, A. (2006). Language Education as Translingual Activismn. Asia Pacific Journal of Education, 26(1), 111-114.

Pennycook, A. (2010). Critical and alternative directions in applied linguistics. Australian Review of Applied Linguistics, 33(2), 1-16

Pennycook, A. (2013). Language policies, language ideologies and local language practices. En Wee, R. B. H. y Lim, L. The Politics of English (1-18). Amsterdam: John Benjamins Publishing Company.

Pérez-Milans, M. y Soto C. (2016). Reflexive language and ethnic minority activism in Hong Kong. A trajectory-based análisis. AILA Review, 29, 48-82.

Phillipson, R. L. (1996): Linguistic Imperialism. Oxford: Oxford University Press.

Piller, I. (2016). Linguistic diversity and social justice. New York: Oxford University Press.

Pinto, M. (1993). Le développement métalinguistique chez les enfants bilingues. Problématiques héoriques et résultats de recherche. Revista Scientia paedagogica experimentalis, 31, 119-47.

Preston, D. R. y Young, R. (2000). Adquisición de segundas lenguas: variación y contexto social. Madrid: Arco/Libros.

Quijano, A. (2007). Colonialidad del poder y clasificación social. En Castro-Gómez, S. y Grosfoguel, R. (Ed.). El giro decolonial: reflexiones para una diversidad epistémica más allá del capitalismo global (93-126). Bogotá: Siglo del Hombre Editores.

Rajagopalan, K. (2003). Por uma lingüística crítica. Linguagem, identidade e a questão crítica. São Paulo: Editorial Parábola.

Rajagopalan, K. (2007). Por uma linguística crítica. Letras \& Letras, 8(14), 13-20.

Rivera, S. (2010a [1984]). Oprimidos, pero no vencidos. Luchas del campesinado aymara y qhechwa 1900- 1980. La Paz: La mirada Salvaje.

Rivera, S. (2010b). Violencias (re)encubiertas en Bolivia. La Paz: Editorial Piedra Rota.

Santana, Á. C., (2014). Línguas cruzadas, histórias que se mesclam. Ações de documentação, valorização e fortalecimento da língua Chiquitana no Brasil. Jundiaí: Paco Editorial.

Santana, Á. C., \& Dunck-Cintra, E. M. (2009). Estudos da língua Chiquitano do Brasil: trajetória e perspectivas. Polifonia, 15(17).

Santos, B. (2010). Refundación del estado en América Latina: Perspectivas desde una epistemología del sur. Lima: Instituto Nacional de Derecho Social.

Santos, B. (2012). De las dualidades a las ecologías. La paz: REMTE.

Santos, B. (2014). Epistemologías del sur: Perspectivas. Madrid: Akal.

Santos, E. (1996). Certo ou errado? Atitudes e crenças no ensino da língua portuguesa. Rio de Janeiro: Graphia. 
Saville-Troike, M. (2003). The ethnography of communication: an introduction. $2^{\mathrm{a}}$ Ed. Oxford: Blackwell.

Schön, D. A. (1983). The reflexive practitioner: How professional sthink in action. New York: Basic Books.

Schön, D. A. (2000 [1998]). Educando o profissional reflexivo. Um novo design para o ensino e a aprendizagem. Porto Alegre: artes Médicas Sul.

Tollefson, W. (2005). Critical Theory in Language Policy. En Ricento. T. (Ed.). (2005). An Introduction to Language Policy: Theory and Method (42-59). Oxford: Blakwell.

Trudgill, P y Hernández, J. M. (2007). Diccionario de sociolingüística. Madrid: Editorial Gredos.

Tunmer, E., y Myhill, M. (1984). Metalinguistic awareness and bilingualism. En Tunmer, W. E., Pratt, C. y Herriman, M. L. (Eds.). Metalinguistic awereness in children (169-87). Berlín: Springer Verlag.

Vertovec, S. (2007). Super-diversity and its implications. Ethnic and Racial Studies, 30(6), 1024-1054.

Williams, R. (1983). Culture. London: Fontana 